\title{
Lacerated Tongue Injury in an Infant: A Case Report
}

\author{
Pratistha Gurung, ${ }^{1}$ Sneha Shrestha, ${ }^{2}$ Mamta Dali, ${ }^{3}$ Bandana Koirala ${ }^{4}$ \\ ${ }^{1}$ Post-graduate Resident, ${ }^{2}$ Assistant Professor, ${ }^{3}$ Associate Professor, ${ }^{4}$ Professor \\ ${ }^{1-4}$ Department of Pedodontics and Preventive Dentistry, College of Dental Surgery, \\ B. P. Koirala Institute of Health Sciences, Dharan, Nepal.
}

\begin{abstract}
Tongue laceration is not uncommon in young children. The most common location for a lacerated tongue injury in children is the anterior dorsum of the tongue. Fall at home is the most common cause of injury. Choosing an optimal treatment option for tongue lacerations remains a challenge due to contradictory recommendations and lack of current guidelines. This case reports the timely intervention and repair of a lacerated tongue injury in an 11-month-old infant under local anesthesia with satisfactory healing where function and esthetics of the tongue was restored. Thus, timely intervention of suturing in lacerated tongue injury in children can give good results.
\end{abstract}

Keywords: Infant, suturing, tongue injury, tongue laceration.

\section{INTRODUCTION}

Tongue is a muscular organ that sits on the floor of the oropharynx and has 3 surfaces: tip, body, and base. The body of the tongue, has dorsal (superior) and ventral (inferior) surfaces. ${ }^{1}$

Tongue lacerations are common among intraoral soft tissue injury in children that can occur from falls at home or as penetrating injuries from sticks or other objects. ${ }^{1}$ The most common location for a lacerated tongue injury in children is the anterior dorsum of the tongue. ${ }^{1}$ The next most common locations are the mid dorsum and anterior ventrum. The frequency of injury reduces from anterior to posterior on both surfaces. ${ }^{2}$

Tongue laceration in children require treatment decisions but there are conflicting reports in the literature on the suturing topic. ${ }^{3}$

\section{Correspondence}

Dr. Pratistha Gurung

Post-graduate Resident,

Department of Pedodontics and Preventive Dentistry,

College of Dental Surgery,

B.P. Koirala Institute of Health Sciences, Dharan, Nepal.

E-mail: pratisthagurungs@gmail.com

Citation

Gurung P, Shrestha S, Dali M, Koirala B. Lacerated Tongue Injury in an Infant: A Case Report. J Nepalese Assoc Pediatr Dent. 2020;1(1):23-6.
Recommendations regarding the appropriate management of tongue lacerations include: ${ }^{4}$

a. Suturing

- Injuries located on both dorsum and lateral border. $^{3}$

- Injuries greater than $2 \mathrm{~cm}$ in length or when hemostasis has not been achieved. ${ }^{5}$

- Deep tongue lacerations in layers using resorbable sutures. ${ }^{4}$

- Tongue lacerations if they are gaping at rest, or involving the lateral border or if there is active hemorrhaging. The application of pressure, cold and inactivity would also help achieve haemostasis. ${ }^{2}$

b. Early intervention, within eight hours of injury to prevent excessive edema. Delaying treatment beyond 24 hours adversely affect the outcome. ${ }^{6}$

c. Small lacerations need not be sutured when wound margins are in good approximation.

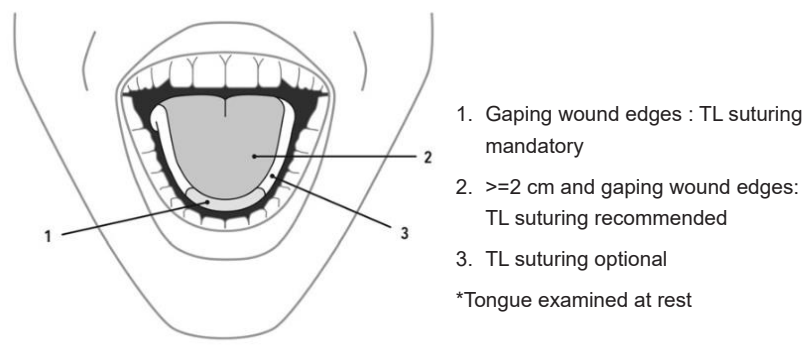

Figure 1. Zurich Tongue Scheme for tongue lacerations in children. 
The Zurich Tongue Scheme $(\mathrm{ZTC})^{8}$ gives an idea of factors that favor repair, ways to repair and common complications to consider in tongue laceration (Figure 1). Tongue injuries with gaping wound edges in a rest position seem to benefit from a primary wound closure. ${ }^{8}$ Lack of timely suturing would pose either delayed healing or unsatisfactory cosmetic outcome especially in lacerations affecting the tip and with a length of more than $2 \mathrm{~cm}$ on the dorsum of the tongue. ${ }^{8}$ But some, warns that suturing may predispose the tongue to invasive, closed space infection. ${ }^{9}$

\section{CASE REPORT}

An 11-month-old male child attended the Pediatric emergency of B.P. Koirala Institute of Health Sciences with an injury in anterior part of tongue after fall from bed one day ago. He was referred to the Department of Pedodontics and Preventive Dentistry for wound evaluation and dental assessment. The child was conscious, but irritable and crying. There was no history of convulsions, vomiting, loss of consciousness, seizures, neck stiffness or injury to any other part of his body. His past medical history was noncontributory. His first tooth appeared at six months of age and according to the mother, he had bitten his tongue during the fall.

Intraoral examination showed erupted upper and lower deciduous central incisors $(51,61,71,81)$ and erupting upper lateral incisors $(52,62)$. The tongue was assessed by standardized examination technique of the tongue in rest position to check whether the wound edges had gaping or not. There was a through and through laceration on anterior tip and lateral border of the tongue involving both the dorsal and ventral aspects, about $3 \mathrm{~cm}$ in largest dimension (Figure 2).

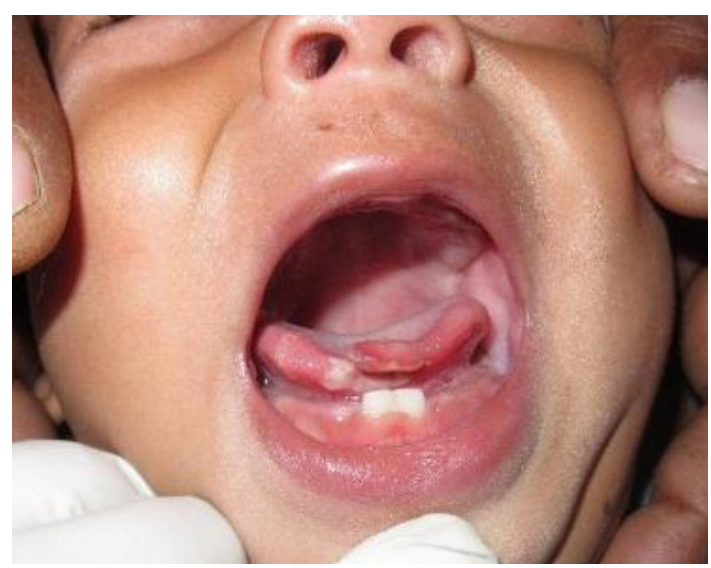

Figure 2. Pre-operative photograph, tongue laceration involving both dorsal and ventral aspects of tip.
Wound debridement and suturing under local anesthesia was planned as the tip of the tongue was in verge of being severed. Due to the lack of baby's cooperation, his little age and urgency of the procedure, decision was taken in favor of the physical containment (protective stabilization) with the informed consent and aid from the parents. During the procedure baby was laid over bed, hands were held by his father and an assistant held the baby's head. The baby was crying continuously with mouth open and this helped in accessibility to the wound during treatment.

A topical anesthetic gel was applied over the wound for three minutes followed by local infiltration of anesthesia (2\% lignocaine with epinephrine 1: 200000; one insulin cartridge) around the cut wound. The tongue was elevated by temporarily passing the 3-0 silk suture over the tongue (Figure 3). Interrupted sutures were placed by using 4-0 vicryl suture over the dorsal and ventral aspect of the cut wound (Figure 4).

Analgesics and antibiotics were prescribed and the patient was recalled to the OPD the next day. The parents were taught about maintenance of oral hygiene for the infant, avoidance of breast feeding for a week and advised for giving soft diet only. The following day, when the patient was reviewed, some sutures were loose and missing from the anterior aspect of the tongue (Figure 5). Hence, resuturing was done under local infiltration of anesthesia with 4-0 vicryl suture (Figure 6). The patient was discharged and reviewed after a week where wound was healing satisfactorily (Figure 7). The patient was followed up after 15 days, one month and two months to ensure complete healing. The wound had healed with no disturbance in function and esthetics of the tongue (Figure 8,9).

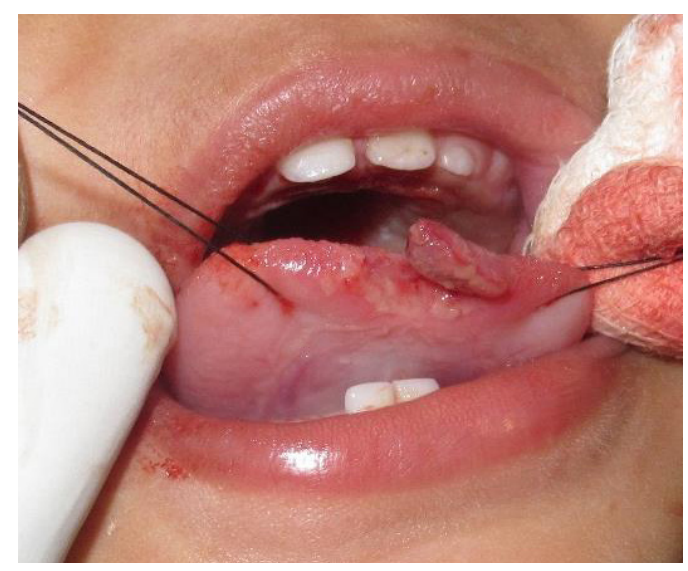

Figure 3. Tongue elevation using silk sutures. 


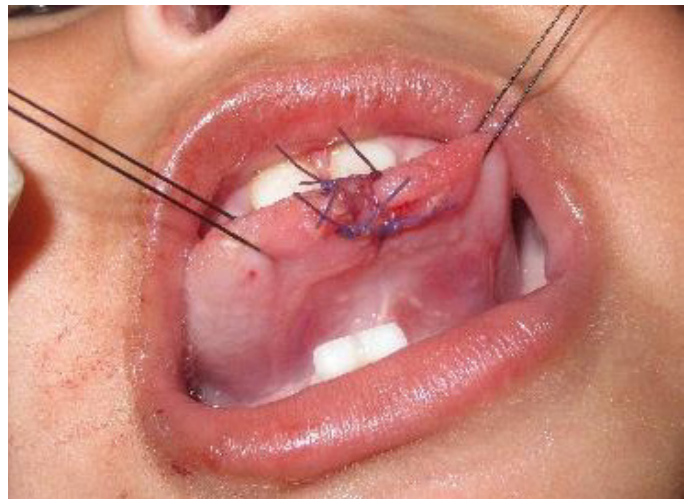

Figure 4. Interrupted suturing using 4-0 vicryl suture.

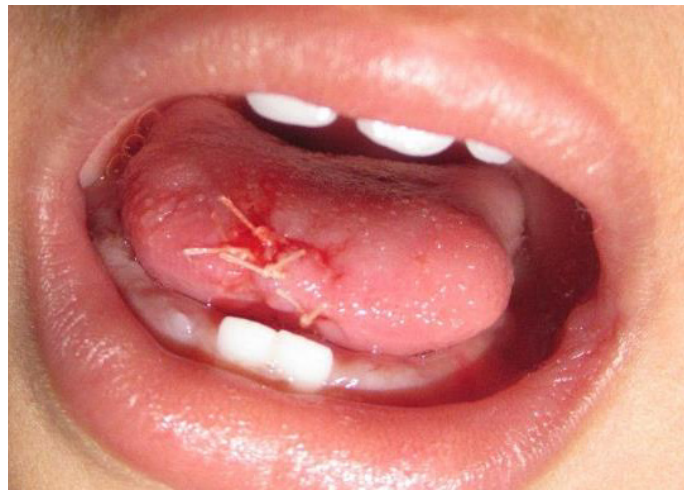

Figure 6. Resuturing with resorbable sutures.

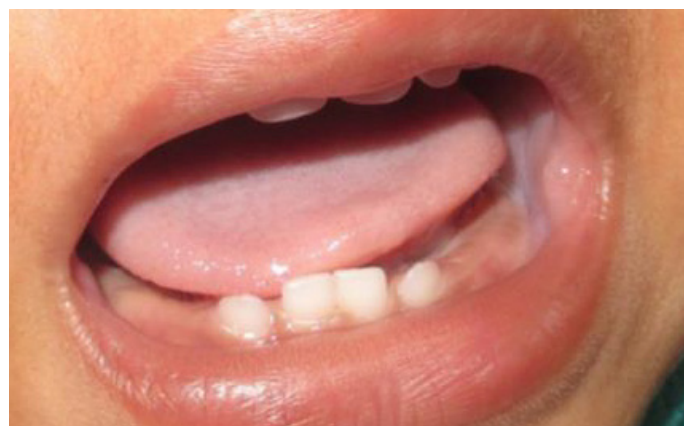

Figure 8. Complete healing after 1 month with function and esthetics of the tongue

(Erupting 72 82).

\section{DISCUSSION}

Tongue lacerations in young children needs careful assessment with its possible related complications, to determine whether a primary wound closure under local or general anesthesia, is required or not. Management principles for soft tissue injuries are much the same except that treatment should be initiated within initial hours to facilitate faster healing. ${ }^{5}$ Immature collagen fibers in the child's soft tissue helps in gaining cosmetic results. A wound located on the dorsal surface of the tongue should always be examined for its ventral counterpart

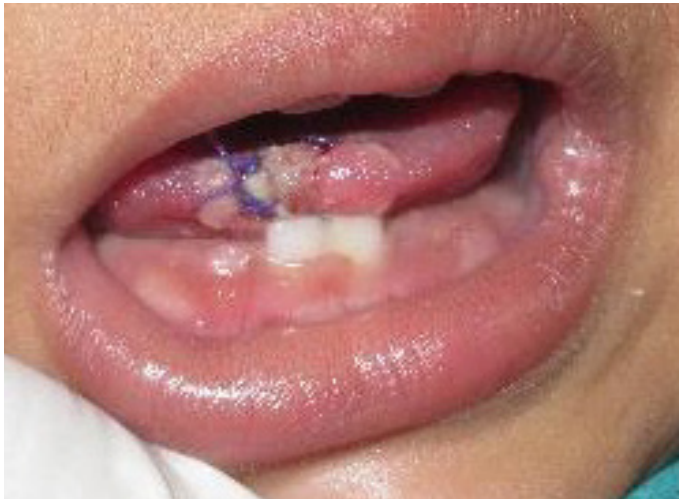

Figure 5. Loosening of sutures at tip of tongue just in a day.

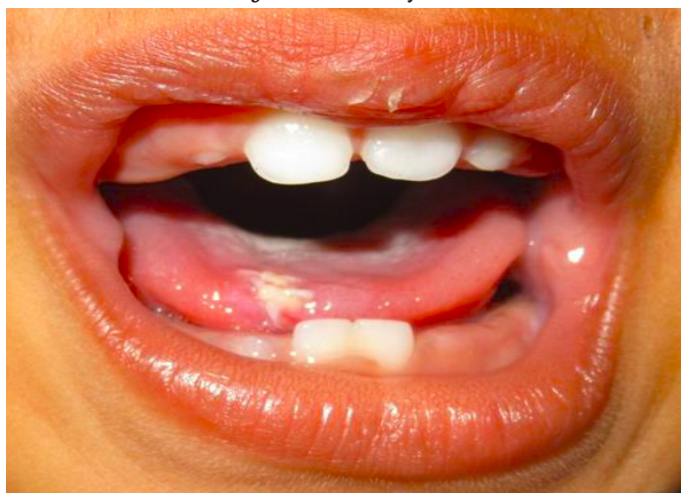

Figure 7. Wound healing after 1 week.

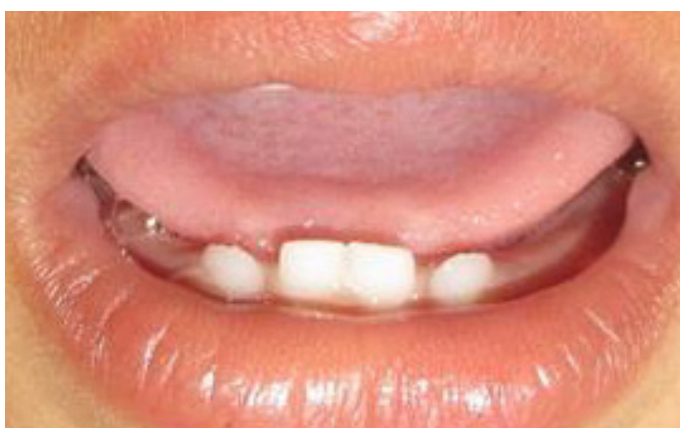

Figure 9. Follow up after 2 months.

too. If there are concomitant crown fractures, pieces of teeth or restoration fragments may be located within the wound. ${ }^{1}$ Hemorrhage and disfigurement are the two most common concerns in these injuries, although loss of function, infection and swelling that compromises the airway are also mentioned as sequelae. ${ }^{7}$ With the tongue's generous blood supply, most tongue lacerations do not become infected and many heal well even without a repair. The goals of laceration repair of the tongue are to attain adequate closure, minimize complications, preserve mobility, and optimize articulation and deglutition. ${ }^{9}$ If the tongue is partially or completely sectioned, this may 
lead to oral cavity dysfunction and dramatic reduction in the quality of life..$^{10}$ Surgical management must achieve, preservation of its function and cosmetic outcome.

\section{CONGLUSIONS}

To repair a lacerated tongue or to allow it to heal by secondary intention, the decision has been left to the clinicians and here due to the urgency of the procedure and precoperative age of the child, after protective stabilization and adequate local anesthesia primary closure of the tongue laceration was done with absorbable sutures which resulted in satisfactory functional and cosmetic outcome in this case.

Conflict of Interest: None

\section{REFERENCES}

1. Das UM, Gadicherla P. Lacerated tongue injury in children. Int J Clin Pediatr Dent. 2008 Sep;1(1):39-41. [PubMed I DOI]

2. Lamell CW, Fraone G, Casamassimo PS, Wilson S. Presenting characteristics and treatment outcomes for tongue lacerations in children. Pediatr Dent. 1999 JanFeb;21(1):34-8. [PubMed]

3. Andreasen JO, Andreasen FM. Dorsum and lateral border injuries. In: Andreasen JO, Andreasen FM, eds. Textbook and Color Atlas of Traumatic Injuries to the Teeth. 3rd ed. St Louis: Mosby-Year Book; 1994: 511-514. [ull Text I DOI]

4. Patel A. Tongue lacerations. Br Dent J. 2008 Apr 12;204(7):355. [PubMed I DOI]

5. Powers MP, BertzJ, Fonseca RJ. Management of soft tissue injuries. In: Fonseca RJ, Walker RV, editors. Oral and maxillofacial trauma. WB Saunders; Philadelphia: 1991. pp. 618-648. [Link]

6. Bank P, Brown A. Fractures of the facial skeleton, 1st ed, Oxford: Wright, 2001 10-13. [Link]

7. English GM. Injury to mouth and larynx. In: English GM, eds. Otolaryngology. 1st ed. New York: Harper and Row; 1976: 463. [Link]

8. Seiler M, Massaro SL, Staubli G, Schiestl C. Tongue lacerations in children: to suture or not? Swiss Med Wkly. 2018 Oct 28;148:w14683. [PubMed I DOI]

9. Touloukian RJ. Pediatric mouth injury. In: Touloukian RJ, eds. 3rd ed. Pediatric Trauma. St Louis: CV Mosby; 1990: 204. [Link]

10. Hernández-MéndezJR, Rodríguez-Luna MR, Guarneros-Zárate JE, Vélez-Palafox M. Traumatic partial amputation of the tongue. Case report and literature review. Ann Med Surg (Lond). 2015 Dec 29;5:110-3. [PubMed I DOI] 